\title{
Allergy - Patients with Atopic Dermatitis Express Themselves Through a Questionnaire
}

This article was published in the following Dove Press journal:

Clinical, Cosmetic and Investigational Dermatology

\author{
Jason Shourick' \\ Charles Taïeb $\mathbb{D}^{2}$ \\ Sophie Seite $\mathbb{D}^{3}$
}

'Département Epidémiologie, Hôpital de Toulouse, Toulouse, France; ${ }^{2}$ Patients Priority Department, European Market Maintenance Assessment, Fontenay Sousbois, France; ${ }^{3}$ La Roche-Posay Dermatological Laboratories, Levallois Perret, France
Correspondence: Charles Taïeb

Patients Priority Department, European

Market Maintenance Assessment,

Fontenay Sous-bois, France

Tel +0033771772100

Email charles.taieb@emma.clinic
Introduction: Allergies are becoming more prevalent across the globe and can be linked to several skin diseases, particularly atopic dermatitis (AD). Disruption of the immune system in the skin can lead to inflammatory diseases such as atopic and contact dermatitis, skin infections, and allergies. This is especially evident in processes such as "atopic march", where in childhood, the development of atopic dermatitis can later lead to food allergies, allergic rhinitis and asthma.

Objective: The aim of this international online survey is to study the link between selfreported doctor-diagnosed AD and allergy prevalence.

Methodology: Our survey queried a representative sample of the general population over the age of 18 from five countries (Brazil, China, Russia, the USA and France).

Results: A total of 9399 participants answered the entire online questionnaire. Among them, 2483 (26.4\%) had an allergy diagnosed by a doctor (1243 with food allergies (13.2\%), 1564 with respiratory allergies (16.6\%) and 1669 with skin allergies (17.7\%)). There were 794 (31.9\%) participants with current $\mathrm{AD}$ in the allergy group and $640(9.25 \%)$ in the group without allergies $(p<0.001)$, and there were 1299 (52.3\%) participants with CAD in the allergy group versus $1368(19.8 \%)$ in the group without allergies $(\mathrm{p}<0.001)$. Multivariate analysis showed ORs of $3.24[2.98,3.63](\mathrm{p}<0.001)$ for current AD and $2.4[2.09,2.74]$ $(\mathrm{p}<0.001)$ for CAD. There was no significant interaction between AD and CAD $(p=0.6)$.

Conclusion: A total of $26.4 \%$ of survey respondents reported having doctor-diagnosed allergies. Among these patients, half reported having AD during childhood, and 1/3 reported having a current $\mathrm{AD}$. $\mathrm{CAD}$ and $\mathrm{AD}$ patients clearly have a higher risk of having an allergy than patients without $\mathrm{CAD}$ or $\mathrm{AD}$.

Keywords: allergy, atopic dermatitis, patient centricity

\section{Introduction}

Allergies are becoming more prevalent across the globe and can be linked to several skin diseases, particularly atopic dermatitis (AD). ${ }^{1}$ While the cause of this increase is not entirely clear, it has been attributed to factors such as stress, use of antibiotics, poor nutrition, growing up in clean and urban homes and exposure to environmental pollution. ${ }^{2}$ It has been known for some time that the skin barrier plays a critical role in excluding allergens, irritants, and pathogens that have the potential to disrupt the immune system and cause allergic sensitization. ${ }^{2}$ Disruption of the immune system in the skin can lead to inflammatory diseases such as atopic and contact dermatitis, skin infections, and allergies. This is especially evident in processes such as "atopic march", where in childhood, the development of atopic dermatitis can later lead to food allergies, allergic rhinitis and asthma. ${ }^{3}$ 
The aim of this international online survey is to study the link between self-reported doctor-diagnosed $\mathrm{AD}$ and allergy prevalence.

\section{Methodology}

Our study queried a representative sample of the general population over the age of 18 from five countries (Brazil, France and Russia: $n=2000$; United States: $n=2050$; China: $\mathrm{n}=3050$ ). Participants were selected with the use of a stratified random sampling method from a database including several million Internet users who agreed to participate in various panel surveys. ${ }^{4}$

All participants were asked to complete a structured digital questionnaire. Because this study used completely anonymized data and did not involve patient contact, institutional review board approval was not required.

However, before answering the questionnaire, each respondent was informed of the nature of the survey, that anonymity would be respected and that no collected information would allow any identification.

The respondents could stop answering the questionnaire at the time of their choice without any explanation.

By answering the questionnaire, the respondent confirmed his or her agreement, and completion of the survey was deemed to be informed consent.

After collecting sociodemographic information, questions were asked about the presence of allergies and atopic dermatitis either currently (AD) or during childhood (CAD). Participants were then asked about the type of allergy they had and whether the allergy was diagnosed by a doctor. We defined an allergy patient only as a patient who had been diagnosed by a doctor. We then used global allergy and each type of allergy as the outcomes of univariate and multivariate logistic regression, adjusting for age and sex. We tested the presence of an interaction between childhood atopic dermatitis and/or current atopic dermatitis and allergy.

\section{Results}

A total of 9399 participants answered the entire online form (4787 women, age $40.9 \pm 14.5$ ). Among them, $2483(26.4 \%)$ had an allergy diagnosed by a doctor (1243 with food allergies (13.2\%), 1564 with respiratory allergies (16.6\%) and 1669 with skin allergies (17.7\%)). There were 794 (31.9\%) participants with current AD in the allergy group and $640(9.25 \%)$ in the group without allergies $(p<0.001)$ and $1299(52.3 \%)$ participants with
CAD in the allergy group versus $1368(19.8 \%)$ in the group without allergies $(\mathrm{p}<0.001)$.

Multivariate analysis for all allergies showed an odds ratio $(\mathrm{OR})$ of $3.24[2.98,3.63](\mathrm{p}<0.001)$ for current $\mathrm{AD}$ and an OR of $2.4[2.09,2.74](\mathrm{p}<0.001)$ for CAD. There was no significant interaction between $\mathrm{AD}$ and $\mathrm{CAD}$ $(\mathrm{p}=0.6)$ (Table 1). The multivariate analysis with respiratory allergy as an outcome showed ORs of 3.51 [3.07, 4.01] for CDA and of $2.25[1.95,2.6]$ for current DA, without interaction $(p=0.8)$ (Table 2). For food and skin allergies, there was a significant interaction between DA and CDA ( $p=0.004$ for food allergies and $\mathrm{p}=0.009$ for skin allergies). Therefore, we presented the results in four groups. For food allergies having neither $\mathrm{AD}$ nor $\mathrm{CAD}$ $(\mathrm{N}=6464,68.7 \%)$ as the reference group, for $\mathrm{AD}$ without CAD ( $\mathrm{N}=1166,12.4 \%)$, the $\mathrm{OR}$ was $3.58[2.56,4.91]$ $(\mathrm{p}<0.001)$; for $\mathrm{CAD}$ without $\mathrm{AD}(\mathrm{N}=1501,15.9 \%)$, the OR was $4.65[3.97,4.46](\mathrm{p}<0.001)$; and for $\mathrm{AD}$ and CAD $(\mathrm{N}=268,2.85 \%)$, the OR was 9.69 [8.27, 11.36] $(p<0.001)$ (Table 3). For skin allergies having neither AD nor $\mathrm{CAD}$ as the reference group, for $\mathrm{AD}$ without $\mathrm{CAD}$, the OR was $4.25[3.17,5.663](\mathrm{p}<0.001)$; for CAD without $\mathrm{AD}$, the $\mathrm{OR}$ was $5.02[4.34,5.81]$; and for $\mathrm{AD}$ and $\mathrm{CAD}$, the OR was $13.8[11.9,16]$ (Table 4).

\section{Conclusion}

In this self-reported survey of a representative sample of the general populations of 5 different countries (Brazil,

Table I Multivariate Analysis of the Association Between Any Allergy and Atopic Dermatitis

\begin{tabular}{|l|l|l|}
\hline & Odds Ratio (OR) [Cl 95\%] & $\mathbf{p}$ \\
\hline Age & $1.02[0.99,1.06]$ & 0.2 \\
Sex & $0.7[0.64,0.78]$ & $<0.001$ \\
DA (N=1434) & $2.4[2.09,2.74]$ & $<0.001$ \\
DA_Childhood (N=2667) & $3.24[2.89,3.63]$ & $<0.001$ \\
\hline
\end{tabular}

Abbreviations: $C A D$, childhood atopic dermatitis; $A D$, atopic dermatitis; $\mathrm{Cl}$, confidence interval.

Table 2 Multivariate Analysis of the Association Between Respiratory Allergy and Atopic Dermatitis

\begin{tabular}{|l|l|l|}
\hline & Odds Ratio (OR) [Cl 95\%] & p \\
\hline Age & $1.02[0.98,1.07]$ & 0.258 \\
Sex & $0.76[0.68,0.86]$ & $<0.00 \mathrm{I}$ \\
AD & $2.25[1.95,2.6]$ & $<0.00 \mathrm{I}$ \\
CAD & $3.5 \mathrm{I}[3.07,4.0 \mathrm{II}]$ & $<0.00 \mathrm{I}$ \\
\hline
\end{tabular}

Abbreviations: $C A D$, childhood atopic dermatitis; $A D$, atopic dermatitis; $\mathrm{Cl}$, confidence interval. 
Table 3 Multivariate Analysis of the Association Between Food Allergies and Atopic Dermatitis

\begin{tabular}{|c|c|c|}
\hline & $\begin{array}{l}\text { Odds Ratio (OR) } \\
\text { [Cl 95\%] }\end{array}$ & $\mathbf{p}$ \\
\hline Age & $1.02[0.98,1.06]$ & 0.387 \\
\hline Sex & $0.57[0.5,0.64]$ & $<0.001$ \\
\hline Neither AD nor CAD $(\mathrm{N}=6464)$ & & \\
\hline$C A D$ without $A D(N=|50|)$ & $5.02[4.34,5.8 I]$ & $<0.001$ \\
\hline$A D$ without $C A D(N=1166)$ & $4.25[3.19,5.66]$ & $<0.001$ \\
\hline$A D$ and $C A D(N=268)$ & $13.77[11.85,16]$ & $<0.001$ \\
\hline
\end{tabular}

Abbreviations: CAD, childhood atopic dermatitis; $A D$, atopic dermatitis; $\mathrm{Cl}$, confidence interval.

Table 4 Multivariate Analysis of the Association Between Skin Allergies and Atopic Dermatitis

\begin{tabular}{|l|l|l|}
\hline & $\begin{array}{l}\text { Odds Ratio (or) } \\
\text { [Cl 95\%] }\end{array}$ & $\mathbf{P}$ \\
\hline Age & $\begin{array}{l}0.94[0.9,0.99] \\
0.7[0.62,0.8]\end{array}$ & $\begin{array}{l}0.01 \\
<0.001\end{array}$ \\
\hline Nex & & \\
CAD without AD $(\mathrm{N}=150 \mathrm{I})$ & $4.65[3.97,5.46]$ & $<0.001$ \\
AD without CAD $(\mathrm{N}=1166)$ & $3.58[2.59,4.95]$ & $<0.001$ \\
AD and CAD $(\mathrm{N}=268)$ & $9.69[8.26,1 \mathrm{I} .35]$ & $<0.001$ \\
\hline
\end{tabular}

Abbreviations: CAD, childhood atopic dermatitis; AD, atopic dermatitis; $\mathrm{Cl}$, confidence interval.

China, Russia, the USA and France), $26.4 \%$ of the survey respondents reported having doctor-diagnosed allergies. Among these patients, half reported having $\mathrm{AD}$ during childhood, and $1 / 3$ reported having a current DA. These patients clearly have a higher risk of having an allergy than patients without $\mathrm{CAD}$ or $\mathrm{AD}$. This is particularly true for allergies as a whole and for respiratory allergies where $\mathrm{CAD}$ and $\mathrm{AD}$ are independent risk factors for having an allergy. This confirmed the importance of the "atopic march" and the need for close follow-up by dermatologists of patients with $\mathrm{CAD}$ and $\mathrm{AD}$ (because there is a strong relationship between $\mathrm{CAD}$ and $\mathrm{AD}$ ) to minimize their risk of developing allergies later in life. Furthermore, $\mathrm{AD}$ is frequently treated with corticosteroids, and minimizing skin barrier dysfunction may be one way to prevent future allergies.

Nevertheless, CAD and current $\mathrm{AD}$ are not the only risk factors for developing allergies; $44.1 \%$ of patients with diagnosed allergies have neither CAD nor current AD. Allergies can develop via transcutaneous sensitization; thus, taking care of primary barrier deficiency in at least some individuals with sensitive skin is of primary importance to limit the prevalence of allergies across the globe. $^{2}$

With the rising prevalence of allergies, it is increasingly important to better characterize their nature and implications. Until the pathogenesis is fully understood, the skin and its barrier function remain important targets for preventive and curative strategies.

\section{Funding}

La Roche-Posay Dermatological Laboratories, France.

\section{Disclosure}

S. Seité is an employee of La Roche-Posay, France. The authors report no other conflicts of interest in this work.

\section{References}

1. Nettis E, Ortoncelli M, Pellacani G, et al. A multicentric study on prevalence of clinical patterns and clinical phenotypes in adult atopic dermatitis. J Investig Allergol Clin Immunol. 2020;30(6). doi:10.18 176/jiaci.0519.

2. Strugar TL, Kuo A, Seité S, Lin M, Lio P. Connecting the dots: from skin barrier dysfunction to allergic sensitization, and the role of moisturizers in repairing the skin barrier. J Drugs Dermatol. 2019;18 (6):581-586.

3. Bantz SK, Zhu Z, Zheng T. The atopic march: progression from atopic dermatitis to allergic rhinitis and asthma. J Clin Cell Immunol. 2014;5.

4. Seité S, Kuo AM, Taieb C, Strugar TL, Lio P. Self-reported prevalence of allergies in the USA and impact on skin-an epidemiological study on a representative sample of american adults. Int $J$ Environ Res Public Health. 2020;17(10):3360. doi:10.3390/ijerph17103360
Clinical, Cosmetic and Investigational Dermatology

\section{Publish your work in this journal}

Clinical, Cosmetic and Investigational Dermatology is an international, peer-reviewed, open access, online journal that focuses on the latest clinical and experimental research in all aspects of skin disease and cosmetic interventions. This journal is indexed on CAS.
The manuscript management system is completely online and includes a very quick and fair peer-review system, which is all easy to use. Visit http://www.dovepress.com/testimonials.php to read real quotes from published authors. 